Review Article

\title{
The role of oxidative stress and the underlying biological pathways in the pathogenesis of Parkinson's Disease
}

\begin{abstract}
In this review, we present evidence collected over a decade concerning signaling pathways and pathogenic mechanisms that are associated with oxidative stress in Parkinson's disease. Parkinson's is associated with several protein such as $\alpha$-synuclein and signaling pathways such as Wnt signaling pathway. The review highlights the connection of the Wnt mediated pathway with other biological pathways that are known to have a role in neurodegeneration and the orchestrated role of several proteins in mitochondrial oxidative stress in Parkinsons. We have highlighted neuroprotective agents that eliminate the excess of reactive oxygen species and have a potential to be developed as therapeutics for Parkinson.
\end{abstract}

Keywords: parkinson's, oxidative stress, natural treatments for parkinson's, biological pathways
Volume I4 Issue I - 202 I

\author{
Chelsea Leonce,' Amrut Patel, ${ }^{2}$ Bela \\ Peethambaran ${ }^{1,2}$ \\ 'Department of Chemistry, University of the Sciences in \\ Philadelphia, USA \\ ${ }^{2}$ Department of Biological Sciences, University of the Sciences in \\ Philadelphia, USA
}

Correspondence: Bela Peethambaran, Department of
Biological Sciences, University of the Sciences in Philadelphia,
Philadelphia, Pennsylvania, 19104, USA,

Email b.peethambaran@usciences.edu

Received: December 22, 2020 | Published: January 22, 2021

\begin{abstract}
Abbreviations: PD, parkinson's disease; iNOS, induced nitric oxide synthase, NO, nitric oxide; PUFAs, polyunsaturated fatty acids

\section{Introduction}

Parkinson's Disease (PD) is a neurodegenerative disease that mainly affects the substantia nigra pars compacta of the brain. ${ }^{1}$ This is the dopamine and melanin producing section of the brain which controls motor skills and in Parkinsons is shown to manifest with symptoms such as tremors, slow mobility and loss of posture and balance. ${ }^{2}$ PD is the second most common neurodegenerative disease after Alzheimer's Disease and affects over one million people worldwide. PD symptoms usually manifest in patients over 50years of age, however, symptoms are seen earlier in patients with genetically caused versions of the disease. Patients with idiopathic forms of PD have unknown cause of disease manifestation but there have been reports of higher cases of PD in persons who work in agricultural and manufacturing industries. ${ }^{3}$ Generally, increased oxidative stress has been linked to the pathology of $\mathrm{PD},{ }^{4}$ however, simply treating patients with antioxidants has not been able to fully reverse or alleviate the progression of the disease. Because of this, current PD treatments serve only to slow the progression of the disease and manage symptoms.
\end{abstract}

Generally, there are two main discussions/models surrounding the pathogenesis of $\mathrm{PD}$, the oxidative stress model, and the genetic mutations model. Though both models focus on different aspects of $\mathrm{PD}$, the consensus is that they both work together to bring about PD pathogenesis. ${ }^{5}$ This pathogenesis causes damage to the substantia nigra neurons, causes a decrease in dopamine production, increase in Lewy body formation and ultimately cell death. ${ }^{6}$ A marked difference can be seen in the neurons of patients with PD (Figure 1). With familial PD, its etiology can be pointed towards many gene mutations including; Parkin, DJ-1, PINK1, LRRK2, a-synuclein, to name a few. ${ }^{7}$ However, there is limited consensus on the etiology of idiopathic PD, and it remains widely unknown. Various mentioned causes for idiopathic PD include brain injury and exposure to various environmental factors such as pesticides and neurotoxins. ${ }^{8,9}$

There are several genes that are implicated in the degeneration of substantia nigra pars compacta. The degeneration is commonly associated with the accumulation of a-synuclein containing Lewy bodies. $^{2}$ Current studies cannot accurately pinpoint a specific mechanism underlying the neurodegenerative cause in PD; however, several studies show a clear role of oxidative stress, mitochondrial dysfunction, and neuronal inflammation. ${ }^{10}$ It is clear from current neurobiology research that oxidative stress products damage DNA, lipids, proteins and many vital macromolecules (Figure 1). Lack of remediation and control of oxidative damage is the prime culprit for neurodegeneration. The downstream effects of these macromolecules damage led to decrease in dopamine a level that causes the classical symptoms such as cognitive impairment, depression, mood fluctuations, psychosis, dementia other than the motor complications seen in Parkinson. This review highlights both the oxidative stress and mutation in key proteins that lead to the pathogenesis of PD. Current drugs to treat Parkinson such as Levodopa, cycrimine, carbinoxamine and carbidopa have led to side effects such as tension, apprehension, lack of balance, lethargy which affects patient's health. Recently, several studies have reported medicinal plant-based therapy. Eight natural compounds that have potential to be developed as therapeutics have been described in detail in this review.

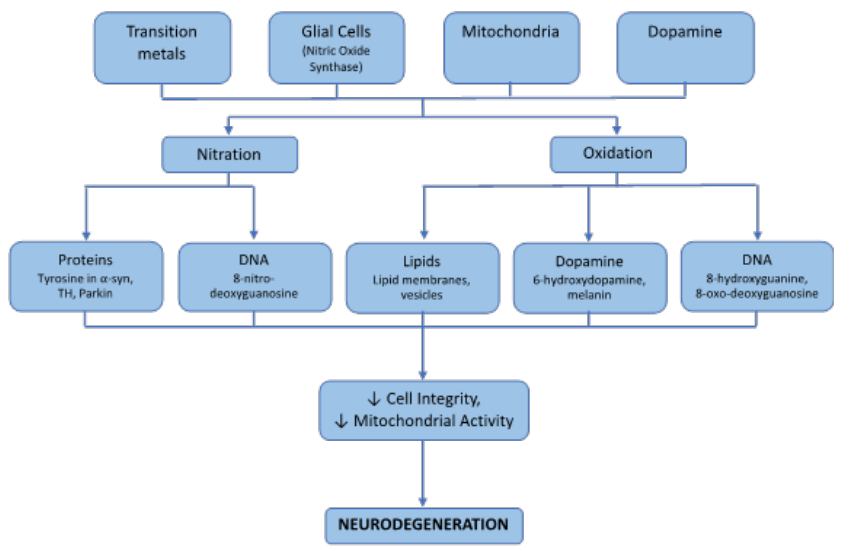

Figure I A flowchart that shows how the production of ROS and RNS caused by transition metals, Glial cells, mitochondria and dopamine can affect many different aspects of structure and activity of cells and lead to neurodegeneration. 


\section{PD oxidative stress model}

\section{Oxidation/nitration of proteins, DNA, lipids and their building blocks}

Uncontrolled production of ROS and RNS causes serious damages to biomolecules. These consequences can be seen in nucleic acids of RNA/DNA, amino acids and specific proteins, various lipids and other key compounds. These alterations in structure based on oxidation and nitration products and formation of adducts have dire effects on metabolism, structure, function and activity of many pathways. ROS and RNS has been known to oxidize or nitrate guanine to 8-hydroxyguanine, 8-nitro-deoxyguanosine and 8-oxodeoxyguanosine and cause deamination of proteins including the change of cytosine to uracil and guanine to xanthine. ${ }^{11-13}$ DNA crosslinks between thymine and tyrosine have also been observed. ${ }^{14}$ These products have been specifically increased in the substantia nigra of the brain and are implicated in mutations that lead to development and progression of $\mathrm{PD}$.

Another key effect of RNS is the nitration of key amino acids, mainly tyrosine to 3-nitrotyrosine. ${ }^{15}$ Nitration usually occurs directly by nitric oxide or peroxynitrates formed through a Haber Weiss reaction involving transition metals. ${ }^{16}$ Tyrosine residues are nitrated at the ortho position on the benzene ring and makes it bulkier. The nitrate also adds a negative charge to the protein, changes its $\mathrm{pKa}$ from 10.01 to 7.2 and prevents protein rotation because of the bulky group. ${ }^{17}$ Increased 3-nitrotyrosine can be observed in alphasynuclein and tyrosine hydroxylase. ${ }^{18,19}$ Nitration of these proteins have an effect on their activity, their structure and their ability to be degraded by proteasomes. 3-nitrotyrosine also has neurotoxic effects on its own after conversion to 3-nitro-4-phenylacetate by amino acid decarboxylase. Through this mechanism, 3-nitrotyrosine causes a decrease in intracellular dopamine levels. ${ }^{20}$ The compound effect of 3 -nitrotyrosine and the nitration of key proteins and enzymes in the $\mathrm{SNc}$ contributes to the degeneration present in PD patients.

ROS and RNS also have other effects including decrease in polyunsaturated fatty acids (PUFAs) and a concurrent increase in oxidation products such as malondialdehyde, 4-hydroxy-2-nonenal and similar byproducts. ${ }^{21,22}$ An increase in protein carbonyls have also been observed. ${ }^{23,24}$ Adducts of cysteine and GSH to levodopa, dopamine and 3,4-dihydroxyphenylacetic acid have been observed. ${ }^{25}$ The formation of quinones and catechol-quinones have also modified cysteine and cysteinyl compounds. ${ }^{26}$ Also, a general decrease in GSH and a subsequent increase in ROS and inhibition of mitochondria has been observed..$^{27,28}$ These effects have been specifically observed and measurable in the SNc of PD patients and can be markers for the development and progress of the disease.

\section{Sources of ROS/RNS}

Mitochondria have been known for a long time to be a source of ROS in living organisms through the process of oxidative phosphorylation. Production of ROS in mitochondria is not innately negative and has been involved in maintaining cellular homeostasis and as signals for many pathways..$^{29}$ Mitochondrial ROS production is based on a balance of $\Delta \mathrm{p}, \mathrm{NADH} / \mathrm{NAD}^{+}, \mathrm{CoQH}_{2} / \mathrm{CoQ}$ and oxygen concentration. ${ }^{30}$ An imbalance in any of these systems can trigger overproduction of ROS leading to oxidative damage and cell death. Mitochondrial $\mathrm{Ca}^{2+}$ also plays a role in the stimulation of oxidative phosphorylation with an increase in $\mathrm{Ca}^{2+}$ causing an increase in respiration.

The major ROS produced in mitochondria is superoxide which then dismutates to produce hydrogen peroxide. These ROS can be damaging on their own but can also go on to produce hydroxyl radicals and react with nitric oxide to produce peroxynitrite. ${ }^{16}$

$$
\begin{aligned}
& \mathrm{O}_{2} \rightarrow \mathrm{O}_{2}^{-\cdot} \rightarrow \mathrm{H}_{2} \mathrm{O}_{2} \rightarrow \mathrm{OH} \rightarrow \mathrm{H}_{2} \mathrm{O} \\
& \text { (1) } \\
& \text { superoxide hydrogen } \\
& \text { 1. } M^{n+}+O_{2}^{-\cdot} \rightarrow M^{n+(-1)}+O_{2} \\
& \text { (2) } \\
& \text { 2. } \mathrm{M}^{n+(-)}+\mathrm{H}_{2} \mathrm{O}_{2} \rightarrow \mathrm{M}^{n+}+\underset{\substack{\text { hydroxyl } \\
\text { radical }}}{\mathrm{HO}}+\mathrm{HO}^{-} \\
& \text {3. } \mathrm{O}_{2}^{-\cdot}+\mathrm{NO} \rightarrow \underset{\text { peroxynitrit }}{\mathrm{ONOO}^{-}} \\
& \text {4. } \mathrm{ONOO}^{-}+\mathrm{H}^{+} \leftrightarrow \mathrm{HOONO} \rightarrow \mathrm{HO}^{\circ}+ \\
& \mathrm{NO}_{2} \\
& M^{n+}=\text { transition metal } \\
& \text { Reactive oxygen and nitrogen species in } \\
& \text { bold }
\end{aligned}
$$

NADH dehydrogenase (Complex I) and Complex III are the major sources of superoxide in the mitochondria and inhibitors such as rotenone, antimycin and cyanide increase superoxide production in these complexes. ${ }^{31}$ Complex I releases superoxide on the matrix side of the mitochondria and Complex III on the cytoplasmic side. ${ }^{32}$ Under physiological condition, manganese-SOD can sequester and neutralize the superoxide produced. If unchecked, ROS can inhibit the electron transport chain, and release iron from the iron-sulfur clusters and other iron storage units in the mitochondria. ${ }^{33}$ The free iron can take part in Fenton reactions and produce more ROS. It is also interesting to note that the substantia nigra has a high level of iron storage and is more susceptible to imbalances in mitochondrial ROS. ${ }^{34}$ Coupled with the high rate of metabolism in neuronal cells, maintaining ROS levels in the mitochondria continues to be a key target for treatment for PD.

\section{Glial cells}

Glial cells are the most abundant cells in the brain and serve many roles. They have been implicated in PD because of their noted activation in PD patients and their ability to produce ROS and RNS and neuronal inflammation. ${ }^{35}$ Microglial activation has been shown to cause an increase in anti-inflammatory cytokines including IL- 6 , TNF- $\alpha$ and INF- $\gamma \cdot{ }^{35-37}$ Glial cells have been shown to be activated by extracellular a-synuclein, neuromelanin and external toxins. A-synuclein is phagocytosed by glial cells where it then activates NADPH oxidase to produce ROS. ${ }^{38}$ Neuromelanin acts as a chemoattractant, drawing microglial to cells which have been damaged and released their stored neuromelanin. Initial neuronal apoptosis also releases activated MMP3 which activates microglia and may cause damage to remaining healthy cells in the direct vicinity. ${ }^{39-41}$ Glial cells can also be activated by rotenone, paraquat, liposaccharides and diesel exhaust. ${ }^{42}$ ROS and RNS produced by glial cells occur through a cascade that starts with the production of induced nitric oxide synthase (iNOS) which then produces nitric oxide (NO). The NO reacts with cellular superoxide to form peroxynitrite. This peroxynitrite then goes on to nitrate amino acid residues in key proteins such as $\alpha$-synuclein, parkin and tyrosine hydroxylase. The nitrosylation of these proteins causes a decrease in their activity and an increase in PD development. ${ }^{17,26,43,44}$

\section{Dopamine oxidation}

The production of dopamine is key for the function and maintenance of fine motor skills. Dopamine is formed in SNc by the hydroxylation and decarboxylation of tyrosine. Normally dopamine 
is sequestered in synaptic vesicles for use and is protected from metabolism. However, free dopamine is subject to metabolism by monoamine oxidase B, catechol-o-methyltransferase and aldehyde dehydrogenase to homovanillic acid. ${ }^{45}$ Dopamine can also undergo autoxidation to make byproducts that are toxic to cells. It is these oxidation products that contribute to the selective deterioration of $\mathrm{SNc}$ neurons and the development of PD. Dopamine autoxidation causes the production of aminochrome/dopachrome through the production of DOPA-semiquinone and DOPA-quinone steps. ${ }^{46}$ These quinones can be formed without the need of catalysts and enzymes but are affected by $\mathrm{pH} \cdot{ }^{47}$ Each step has the ability to produce ROS in the form of superoxide and hydrogen peroxides. Dopamine oxidation can also be catalyzed by peroxidase enzymes and metals such as copper and iron to produce dopachrome products. ${ }^{48-51}$ One key oxidation product of dopamine is 6-hydroxydopamine, which is shown in high levels in PD patients and is used as a model for PD in research..$^{52,53}$

The overproduction of dopamine oxidation products has numerous effects on the neuronal cell. Dopachrome causes an increase on the production of melanin which was shown to cause an increase in lysosomal dysfunction and decreased lysosomal proteolysis and a concurrent increase in alpha-synuclein aggregation. ${ }^{54}$ Oxidative products also formed adducts directly with alpha-synuclein and increased likelihood of aggregation. ${ }^{54,55}$ Dopamine oxidation also causes a decrease in mitochondrial potential and activity and mitochondrial phosphorylation. ${ }^{56,57} \mathrm{~A}$ decrease in mitochondrial activity causes an increase in ROS and apoptotic signals. Therefore, management of dopamine oxidation and its products could be a viable target for treatment for PD.

\section{Tyrosine hydroxylase}

Peroxynitrite and nitrogen dioxide are able to nitrate the tyrosine residues on tyrosine hydroxylase (TH) and inhibit enzymatic activity. ${ }^{19,23}$ Since $\mathrm{TH}$ is the limiting step in dopamine production, inhibition of the enzyme means a decrease in dopamine and a subsequent increase in PD development/symptoms. Nitration is likely to occur on one of the 15 residues in the active site of $\mathrm{TH}$ and the change in size, $\mathrm{pKa}$ and charge of the residues would have a great effect on enzyme activity by limiting the ability of the enzyme to be phosphorylated. ${ }^{26}$ Peroxynitrite can also react with the copper in SOD to produce toxic nitronium dioxide ions which can then react with the proton on SOD's only tyrosine to form 3-nitrotyrosine. ${ }^{58}$

\section{Alpha-synuclein}

A-synuclein can be nitrated at tyrosine residues to form nitrosylated a-synuclein and is a key target of increased nitric oxide moieties in neuronal cells. ${ }^{43}$ Nitrosylated a- synuclein shows decreased solubility, increased fibrillization and slower degradation of the protein when exposed to $20 \mathrm{~S}$ and Calpain I proteasomes. ${ }^{17,43}$ A decrease in $\alpha$-synuclein monomers to bind to vesicles was also observed. ${ }^{17}$ These effects play a key role in PD pathogenesis as an increase in a-synuclein causes aggregation which is a key signal of PD progression. A decrease in $\alpha$-synuclein binding to lipid vesicles causes a decrease in the ability for neurotransmitters, such as dopamine, to be released from neuronal cells and illicit their appropriate reactions for neuronal excitation and maintenance of motor functions. ${ }^{17}$

\section{Parkin}

Parkin is another protein that is affected by nitration. Parkin is an E3 ligase responsible for adding ubiquitin to substrates for degradation. Parkin undergoes s-nitrosylation by nitric oxide. This diminishes the ligase activity of parkin and its protective effect by allowing an increase in $\alpha$-synuclein aggregation. ${ }^{44,59}$

\section{Biological pathways that play a key role in pathogenesis of PD}

PI3K/AKT signaling pathway: Recent studies have also drawn attention to the possible role of the serine threonine kinase, AKT having a mechanistic role of signaling in defective neuronal cells (Figure 2). There are several key activators of the AKT pathway via phosphatidylinositol 3-kinase (PI3-K) caused by increases or decreases to growth factors, cell stress, and insulin ${ }^{60}$ this causes an upregulation of phosphatidylinositol $(3,4,5)$ P3 (PIP-3), which then leads to recruitment of Akt to the plasma membrane, where phosphorylation at serine-473 and threonine-308 induces Akt activation. Upon activation Akt has many binding sites which all play key roles in the functionality of neuronal cells such as metabolism and cell survival, these substrates include the protein complex mTOR, CREB, BAD, and GSK3b. The impact AKT phosphorylation has on the downstream proteins is incredibly important. Many drug targets that could potentially alleviate PD symptoms have been shown to be neuroprotective via AKT activation. ${ }^{61}$ Expectedly, expression of active phosphorylated AKT protects against induced dopaminergic cell death brought on by 6-hydroxydopamine (6-OHDA). ${ }^{62}$ Previous studies have also elucidated that decreased AKT activation brought on by the induction of the RTP 801 protein, increased PD pathogenesis. ${ }^{63}$

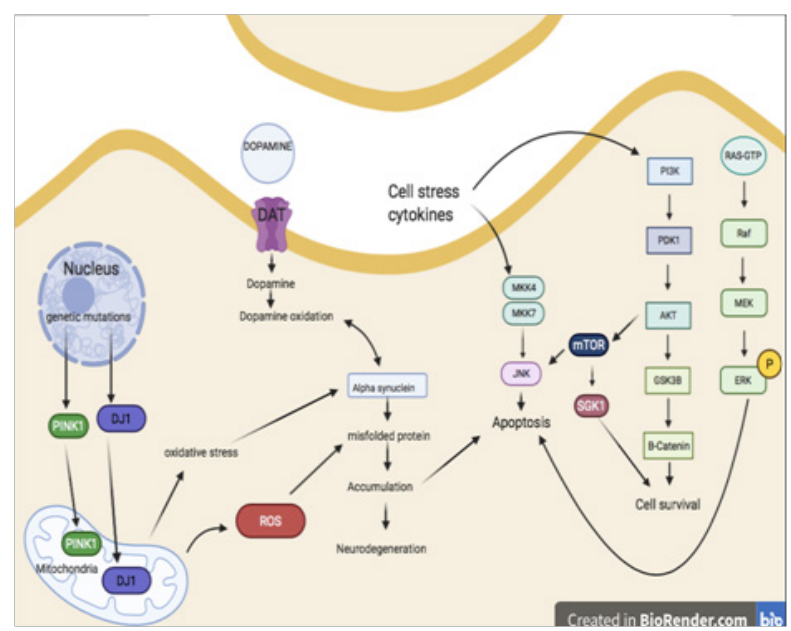

Figure 2 Summarizes the biological pathways that play a key role in alleviation of oxidative stress in Parkinson's.

Mitogen-activated protein kinase signaling pathway: The mitogenactivated protein kinase family (MAPK) is an old, evolutionarily highly conserved family of serine/threonine protein kinases liable for intracellular signaling. The MAPK proteins ${ }^{64}$ survival, cell death, stress response and gene expression. ${ }^{65}$ The extracellular signal-regulated kinases 1 and 2 (ERK1/2) signaling pathway is a fundamental moderator of various cellular processes, this pathway is activated by several different growth factors, $\mathrm{G}$ protein-coupled receptors (GPCRs), insulin, and stress factors. ${ }^{65}$

ERK $1 / 2$ signaling cascade is heavily involved in neuronal death, which is a major cause in all diseases of the neurodegenerative nature including PD. ${ }^{66}$ In regard to PD there are several ERK 1/2 processes that affect $\mathrm{PD}$ pathology such as mitochondrial dysfunction, inflammation, neuroprotection, oxidative stress, cell survival and apoptosis. In terms of mitochondrial dysfunction, recent studies have 
found that PD patients have a mild deficiency in the mitochondrial complex I, within the substantia nigra. ${ }^{64}$ p-ERK $1 / 2$ was also found in the mitochondria of actively degenerated neurons originating from patients with Lewy body dementia and patients with $\mathrm{PD} .{ }^{67}$ There is an orchestrated signaling of all these proteins that affects the oxidative stress (Fig2).

\section{Genetic causes in PD}

Majority of PD cases are idiopathic however a small percentage of them result from highly specific genetic mutations. Familiar or genetic PD typically presents with the same clinical symptoms as idiopathic PD with the key difference being earlier onset of the disease. ${ }^{68}$ There are several genes that code for SNCA ( $S N C A)$, ubiquitin carboxyl terminal hydrolase L1 (UCH-LI), leucine rich repeat kinase 2 (LRRK2) are heavily involved in the autosomal dominant forms, where genes coding for parkin $(P R K N)$, ATPase type 13A2 (ATP13A2), PTENinduced putative kinase 1 (PINK1), and PD associated protein DJ-1 (PRKN7) are heavily involved in autosomal recessive forms of PD. ${ }^{69}$ Many of these genes play significant roles in mitochondrial function, protein ubiquitination, and oxidative stress, these genes also interact with each other. SNCA was the first PD gene to be mapped. This led to the discovery that the encoded protein is the primary component of Lewy bodies. SNCA is a relatively small protein with a $\mathrm{kDa}$ of 14.46 , when overexpressed via triplication and duplication of the gene, SNCA, is associated with DA neuronal toxicity in humans with PD. ${ }^{69}$

Mutations in the gene encoding for LRRK2 have been recently linked with late the late-onset, autosomal dominant form of familial PD. The protein LRRK2 is often looked into as a promising target for therapeutic treatment of PD. Much like SNCA, the precise function of LRRK2 remains largely unknown. LRRK2 is complex and unusually large, with many protein-interaction, and enzymatic domains. ${ }^{70}$ These multiple domains can potentially be targeted by mutations in familial PD. In recent studies LRRK2 increased kinase activity is often linked with neuronal cell death, cellular toxicity and gain of function point mutations, which is observed in both idiopathic and familial PD. Although LRRK2 mutations do not aide in the formation of Lewy bodies, they do however constitute a large share of genetic mutations related to familial $\mathrm{PD} .^{71}$
PINK1, DJ-1 and PRKN are responsible for the autosomal recessive form of PD. PRKN is a cytoplasmic protein primarily, that functions in tagging proteins for proteasomal degradation. Mutations in PRKN are thought to weaken its ability to interact with E3 ubiquinating enzymes, this impaired interaction leads to a build-up of proteins that are unable to be cleared leading to neuronal cell death overtime. ${ }^{72}$ PRKN, PINK1 and DJ-1 are all involved in pathways that regulate mitochondrial function, clearing, morphology and damage in $\mathrm{PD} .^{73}$ PINK1 is a mitochondrial protein that regularly interacts with DJ-1 to modulate the activity of PRKN to aide in protein ubiquitination. When a loss of function mutation occurs in PINK1 it hinders the role of the protein in a mitochondrial quality control pathway, leading to eventual mitochondrial dysfunction and neuronal cell death. ${ }^{74}$ DJ-1 functions to maintain the functionality and integrity of the mitochondria against oxidative stress. ${ }^{75}$ There are various other genes implicated in their respective role in the etiology of $\mathrm{PD}$, however, there is relatively little known regarding their actual function. Although there has been considerable progress in the identification of genes implicated in PD, the functionality of these genes needs to be further investigated.

\section{Natural compounds in the management of Parkinson}

The discovery of levodopa has allowed for great strides towards the treatment of PD and extension of patients' life. However, because of the side effects of continued use and its inability to cure PD, natural products have been used, individually and in conjunction with drugs, to treat PD and lessen its effects. Natural products have been known to decrease tremors and increase mental function. Plants such as Mucuna pruriens, Hyoscyamus niger, Sida cordifolia and Withania somnifera have been used extensively to treat PD. M. pruriens seed extract showed effect as a metal chelator and antioxidant. H. niger seed extract had an anticholinergic effect and the active compounds isolated were hyoscine and hyoscyamine. S. cordifolia and W. somnifera root extracts had antioxidant effects. Other plants showing promising effects as antioxidants and mitochondrial protectants include $C$. asiatica, B. monnieri, S. suaveolens, T. cordifolia and N. jatamausi. Other plants consumed, that focus on consuming high amounts of antioxidants, such as Gingko biloba, green teas and berries, have also been used to help treat and slow the progression of PD (Table 1). ${ }^{76,77}$

Table I Role of natural neuroprotective compounds that have potential to treat Parkinson's Disease

\begin{tabular}{|c|c|c|c|}
\hline Compound name & Target & Mechanism & References \\
\hline $\mathrm{N}$-acetyl cysteine & $\begin{array}{l}\text { Provides cysteine to } \\
\text { maintain GSH levels } \\
\text { Antioxidant }\end{array}$ & $\begin{array}{l}\text { Acts mainly as a pro-drug to provide cysteine for the } \\
\text { production of GSH. Maintains high GSH levels and } \\
\text { protects against } \mathrm{OH}, \mathrm{H}_{2} \mathrm{O}_{2} \text { and } \mathrm{HOCl} \text {. }\end{array}$ & 78-83 \\
\hline EGCG & Antioxidant & $\begin{array}{l}\text { Protects TH producing cells and TH activity which allows } \\
\text { for production of dopamine and metabolites. } \\
\text { Decreased levels of nNOS and iNOS. Decreased } \\
\text { fibrillogenesis of } \alpha \text {-synuclein. }\end{array}$ & $84-89$ \\
\hline CoQIO & $\begin{array}{l}\text { Increased mitochondrial } \\
\text { function } \\
\text { Antioxidant }\end{array}$ & $\begin{array}{l}\text { Protects mitochondria by maintaining integrity and } \\
\text { decreasing ROS formation. }\end{array}$ & $90-95$ \\
\hline $\begin{array}{l}\text { Withanone, Withafarin, } \\
\text { Withanolides (Withania } \\
\text { somnifera) }\end{array}$ & Antioxidant & $\begin{array}{l}\text { Increase SOD, CAT and GPx activity } \\
\text { Free radical scavenging } \\
\text { Increase catecholamine levels } \\
\text { Maintains mitochondrial integrity }\end{array}$ & $96-102$ \\
\hline $\begin{array}{l}\text { Ginsenosides } \\
\text { (Panax ginseng) }\end{array}$ & $\begin{array}{l}\text { Antioxidant } \\
\text { Anti-inflammatory }\end{array}$ & $\begin{array}{l}\text { Reduced inflammation by inhibiting Nitric oxide synthase } \\
\text { and decreasing levels of pro-inflammatory cytokines. } \\
\text { Increased cell viability }\end{array}$ & $103-107$ \\
\hline
\end{tabular}


Table continued...

\begin{tabular}{|c|c|c|c|}
\hline Compound name & Target & Mechanism & References \\
\hline $\begin{array}{l}\text { Ginkgolides } \\
\text { (Ginkgo biloba) }\end{array}$ & $\begin{array}{l}\text { Increased dopamine levels } \\
\text { Antioxidant } \\
\text { Increased mitochondrial } \\
\text { function }\end{array}$ & $\begin{array}{l}\text { Increased dopamine levels through regulation of dopamine } \\
\text { genes and transcription factors } \\
\text { Maintains mitochondrial potential and limits mitochondria- } \\
\text { related ROS production }\end{array}$ & $108-111$ \\
\hline $\begin{array}{l}\text { Baicalein, Baicalin } \\
\text { (Scutellaria baicalensis) }\end{array}$ & $\begin{array}{l}\text { Antioxidant } \\
\text { Increased mitochondrial } \\
\text { function } \\
\text { Reduces levels of } \\
\text { Apoptosis } \\
\text { Increased dopamine levels }\end{array}$ & $\begin{array}{l}\text { Protects mitochondrial membrane from insult } \\
\text { Reduces levels of ROS through activation of ROS- } \\
\text { scavenging enzymes } \\
\text { Reduces apoptosis through management of caspase and } \\
\text { JNK }\end{array}$ & $112-115$ \\
\hline Hyoscyamus niger & Antioxidant & Increase ROS-scavenging enzyme activity, reduced ROS & $116-118$ \\
\hline
\end{tabular}

\section{Conclusions}

The mechanisms involved in pathogenesis and progression of PD is not fully understood but there is overwhelming evidence that maintenance of redox potential is important for neuronal survival. Any disruption in the mitochondrial potential disrupts the cellular homeostasis, which in turn causes more ROS production leading to neuroinflammation and degeneration. The review attempts to consolidate key signaling pathways, and proteins that can be targeted to develop therapeutics for Parkinson's. The conventional medicine is effective but has several side effects; hence developing small molecules that can modify these molecular targets selectively can be explored.

\section{Acknowledgements}

This study was supported by funds from the Endowed Funds for the Roth Chair in Pharmacognosy awarded to Dr. Bela Peethambaran by The University of the Sciences.

\section{Conflicts of interest}

The authors declared no potential conflicts of interest with respect to the research, authorship, and/or publication of this article.

\section{Funding}

None.

\section{References}

1. Braak H, Tredici KD, Rüb U, et al. Staging of brain pathology related to sporadic Parkinson's disease. Neurobiol Aging. 2003;24(2):197-211.

2. Olanow CW, Tatton WG. Etiology and Pathogenesis of Parkinson's Disease. Аппи Rev Neurosci. 1999;22(1):123-144.

3. Elbaz A, Tranchant C. Epidemiologic studies of environmental exposures in Parkinson's disease. J Neurol Sci. 2007;262(1-2):37-44.

4. Jenner P. Oxidative stress in Parkinson's disease. Ann Neurol. 2003;53(S3):S26-S38.

5. Zhang Y, Dawson VL, Dawson TM. Oxidative Stress and Genetics in the Pathogenesis of Parkinson's Disease. Neurobiol Dis. 2000;7(4):240250 .

6. Forno LS. The Neuropathology of Parkinson's Disease. In: Hefti F, Weiner WJ, editors. Progress in Parkinson Research. Boston, MA: Springer US; $1988 ; 11-21$.

7. Moore DJ, West AB, Dawson VL, et al. Molecular Pathophysiology of Parkinson's Disease. Аnnu Rev Neurosci. 2005;28(1):57-87.
8. Tanner CM, Goldman SM. Epidemiology of Parkinson's Disease. Neurologic Clinics. 1996;14(2):317-335.

9. Langston JW, Ballard P, Tetrud JW, et al. Chronic Parkinsonism in humans due to a product of meperidine-analog synthesis. Science. 1983;219(4587):979-980.

10. Bhat AH, Dar KB, Anees S, et al. Oxidative stress, mitochondrial dysfunction and neurodegenerative diseases; a mechanistic insight. Biomed Pharmacother. 2015;74:101-110.

11. Alam ZI, Jenner A, Daniel SE, et al. Oxidative DNA Damage in the Parkinsonian Brain: An Apparent Selective Increase in 8-Hydroxyguanine Levels in Substantia Nigra. $J$ Neurochem. 2002;69(3):1196-1203.

12. Dedon PC, Tannenbaum SR. Reactive nitrogen species in the chemical biology of inflammation. Archives of Biochemistry and Biophysics. 2004;423(1):12-22.

13. Zhang J, Perry G, Smith MA, et al. Parkinson's Disease Is Associated with Oxidative Damage to Cytoplasmic DNA and RNA in Substantia Nigra Neurons. Am J Pathol. 1999;154(5):1423-1429.

14. Henle ES, Linn S. Formation, Prevention, and Repair of DNA Damage by Iron/Hydrogen Peroxide. J Biol Chem. 1997;272(31):19095-19098.

15. Good PF, Hsu A, Werner P, et al. Protein Nitration in Parkinson's Disease. J Neuropathol Exp Neurol. 1998;57(4):338-342.

16. Pennathur S, Jackson-Lewis V, Przedborski S, et al. Mass Spectrometric Quantification of 3-Nitrotyrosine, ortho-Tyrosine, and o, $\mathrm{o}^{\prime}-$ Dityrosine in Brain Tissue of 1-Mlethyl-4-phenyl-1,2,3,6-tetrahydropyridinetreated Mice, a Model of Oxidative Stress in Parkinson's Disease. J Biol Chem. 1999;274(49):3462-34628.

17. Hodara R, Norris EH, Giasson BI, et al. Functional Consequences of $\alpha$ Synuclein Tyrosine Nitration: Diminished Binding to Lipid Vesicles and Increased Fibril Formation. J Biol Chem. 2004;279(46):47746-47753.

18. Duda JE, Giasson BI, Chen Q, et al. Widespread Nitration of Pathological Inclusions in Neurodegenerative Synucleinopathies. Am J Pathol. 2000;157(5):1439-1445.

19. Ara J, Przedborski $\mathrm{S}$, Naini $\mathrm{AB}$, et al. Inactivation of tyrosine hydroxylase by nitration following exposure to peroxynitrite and 1methyl-4-phenyl-1,2,3,6-tetrahydropyridine (MPTP). Proc Natl Acad Sci U S A. 1998;95(13):7659-7663.

20. Blanchard-Fillion B, Prou D, Polydoro M, et al. Metabolism of 3Nitrotyrosine Induces Apoptotic Death in Dopaminergic Cells. $J$ Neurosci. 2006;26(23):6124-6130.

21. Dexter DT, Carter CJ, Wells FR, et al. Basal Lipid Peroxidation in Substantia Nigra Is Increased in Parkinson's Disease. $J$ Neurochem. 1989;52(2):381-389. 
22. Yoritaka A, Hattori N, Uchida K, et al. Immunohistochemical detection of 4-hydroxynonenal protein adducts in Parkinson disease. Proc Natl Acad Sci U S A. 1996;93(7):2696-2701.

23. Alam ZI, Daniel SE, Lees AJ, et al. A Generalised Increase in Protein Carbonyls in the Brain in Parkinson's but Not Incidental Lewy Body Disease. J Neurochem. 2002;69(3):1326-1329.

24. Floor E, Wetzel MG. Increased Protein Oxidation in Human Substantia Nigra Pars Compacta in Comparison with Basal Ganglia and Prefrontal Cortex Measured with an Improved Dinitrophenylhydrazine Assay. $J$ Neurochem. 2002;70(1):268-275.

25. Spencer JPE, Jenner P, Daniel SE, et al. Conjugates of Catecholamines with Cysteine and GSH in Parkinson's Disease: Possible Mechanisms of Formation Involving Reactive Oxygen Species. J Neurochem. 2002;71(5):2112-2122.

26. Park S, Geddes TJ, Javitch JA, et al. Dopamine Prevents Nitration of Tyrosine Hydroxylase by Peroxynitrite and Nitrogen Dioxide: Is Nitrotyrosine Formation an Early Step in Dopamine Neuronal Damage? J Biol Chem. 2003;278(31):28736-28742.

27. Chinta SJ, Kumar MJ, Hsu M, et al. Inducible Alterations of Glutathione Levels in Adult Dopaminergic Midbrain Neurons Result in Nigrostriatal Degeneration. J Neurosci. 2007;27(51):13997-4006.

28. Jha N, Jurma O, Lalli G, et al. Glutathione Depletion in PC12 Results in Selective Inhibition of Mitochondrial Complex I Activity: Implications for Parkinson's Disease. J Biol Chem. 2000;275(34):26096-26101.

29. Hamanaka RB, Chandel NS. Mitochondrial reactive oxygen species regulate cellular signaling and dictate biological outcomes. Trends Biochem Sci. 2010;35(9):505-513.

30. Murphy MP. How mitochondria produce reactive oxygen species. Biochem J. 2009;417(1):1-13.

31. Turrens JF, Boveris A. Generation of superoxide anion by the NADH dehydrogenase of bovine heart mitochondria. Biochem $J$. 1980;191(2):421-427.

32. St-Pierre J, Buckingham JA, Roebuck SJ, et al. Topology of Superoxide Production from Different Sites in the Mitochondrial Electron Transport Chain. J Biol Chem. 2002;277(47):44784-44790.

33. Mastroberardino PG, Hoffman EK, Horowitz MP, et al. A novel transferrin/TfR2-mediated mitochondrial iron transport system is disrupted in Parkinson's disease. Neurobiol Dis. 2009;34(3):417-431.

34. Götz ME, Double K, Gerlach M, et al. The Relevance of Iron in the Pathogenesis of Parkinson's Disease. Ann N Y Acad Sci. 2004;1012(1):193-208

35. Iravani MM, Sadeghian M, Leung CCM, et al. Lipopolysaccharideinduced nigral inflammation leads to increased IL-1 $\beta$ tissue content and expression of astrocytic glial cell line-derived neurotrophic factor Neurosci Lett. 2012;510(2):138-142.

36. Brodacki B, Staszewski J, Toczyłowska B, et al. Serum interleukin (IL-2, IL-10, IL-6, IL-4), TNF $\alpha$, and INF $\gamma$ concentrations are elevated in patients with atypical and idiopathic parkinsonism. Neurosci Lett. 2008;441(2):158-162.

37. Hunot S, Dugas N, Faucheux B, et al. FceRII/CD23 Is Expressed in Parkinson's Disease and Induces, In Vitro, Production of Nitric Oxide and Tumor Necrosis Factor- $\alpha$ in Glial Cells. $J$ Neurosci. 1999;19(9):3440-3447.

38. Zhang W, Wang T, Pei Z, et al. Aggregated $\alpha \square$ synuclein activates microglia: a process leading to disease progression in Parkinson's disease. FASEB J. 2005;19(6):533-542.

39. Wilms H, Rosenstiel P, Sievers J, et al. Activation of microglia by human neuromelanin is NF $\square \kappa \mathrm{B} \square$ dependent and involves p38 mitogen activated protein kinase: implications for Parkinson's disease. FASEB J. 2003;17(3):1-20.
40. Kim YS, Kim SS, Cho JJ, et al. Matrix Metalloproteinase A -3: A Novel Signaling Proteinase from Apoptotic Neuronal Cells That Activates Microglia. J Neurosci. 2005;25(14):3701-3711.

41. Kim YS, Choi DH, Block ML, et al. A pivotal role of matrix metalloproteinase $\square 3$ activity in dopaminergic neuronal degeneration via microglial activation. FASEB J. 2007;21(1):179-187.

42. Block ML, Zecca L, Hong JS. Microglia-mediated neurotoxicity: uncovering the molecular mechanisms. Nat Rev Neurosci. 2007;8(1):5769.

43. Giasson BI. Oxidative Damage Linked to Neurodegeneration by Selective alpha -Synuclein Nitration in Synucleinopathy Lesions. Science. 2000;290(5493):985-989.

44. Chung KKK. S-Nitrosylation of Parkin Regulates Ubiquitination and Compromises Parkin's Protective Function. Science. 2004;304(5675):1328-1331.

45. Meiser J, Weindl D, Hiller K. Complexity of dopamine metabolism. Cell Commun Signal. 2013;11(1):34.

46. Muñoz P, Huenchuguala S, Paris I, et al. Dopamine Oxidation and Autophagy. Parkinsons Dis. 2012;2012:1-13.

47. Umek N, Geršak B, Vintar N, et al. Dopamine Autoxidation Is Controlled by Acidic pH. Front Mol Neurosci. 2018;11:467.

48. Foppoli C, Coccia R, Cini C, et al. Catecholamines oxidation by xanthine oxidase. Biochim Biophys Acta. 1997;1334(2-3):200-206.

49. Galzigna L, De Iuliis A, Zanatta L. Enzymatic dopamine peroxidation in substantia nigra of human brain. Clin Chim Acta. 2000;300(1-2):131138.

50. Paris I, Martinez-Alvarado P, Cárdenas S, et al. Dopamine-Dependent Iron Toxicity in Cells Derived from Rat Hypothalamus. Chem Res Toxicol. 2005;18(3):415-419.

51. Paris I, Dagnino-Subiabre A, Marcelain K, et al. Copper neurotoxicity is dependent on dopamine-mediated copper uptake and one-electron reduction of aminochrome in a rat substantia nigra neuronal cell line: Dopamine-mediated Cu-toxicity. J Neurochem. 2001;77(2):519-529.

52. Napolitano A, Crescenzi O, Pezzella A, et al. Generation of the Neurotoxin 6-Hydroxydopamine by Peroxidase/H2O2 Oxidation of Dopamine. J Med Chem. 1995;38(6):917-922.

53. Anichtchik OV, Kaslin J, Peitsaro N, et al. Neurochemical and behavioural changes in zebrafish Danio rerio after systemic administration of 6hydroxydopamine and 1-methyl-4-phenyl-1,2,3,6-tetrahydropyridine: Effects of MPTP and 6-OHDA on zebrafish brain. $J$ Neurochem 2003;88(2):443-453.

54. Burbulla LF, Song P, Mazzulli JR, et al. Dopamine oxidation mediates mitochondrial and lysosomal dysfunction in Parkinson's disease. Science. 2017;357(6357):1255-1261

55. Pham CLL, Leong SL, Ali FE, et al. Dopamine and the Dopamine Oxidation Product 5,6-Dihydroxylindole Promote Distinct On-Pathway and Off-Pathway Aggregation of $\alpha$-Synuclein in a $\mathrm{pH}$-Dependent Manner. J Mol Biol. 2009;387(3):771-785.

56. Hossain Khan F, Sen T, Maiti AK, et al. Inhibition of rat brain mitochondrial electron transport chain activity by dopamine oxidation products during extended in vitro incubation: Implications for Parkinson's disease. Biochim Biophys Acta. 2005;1741(1-2):65-74.

57. Jana S, Sinha M, Chanda D, et al. Mitochondrial dysfunction mediated by quinone oxidation products of dopamine: Implications in dopamine cytotoxicity and pathogenesis of Parkinson's disease. Biochim Biophys Acta. 2011;1812(6):663-673.

58. Beckman JS, Ischiropoulos H, Chen J, et al. Nitric Oxide as A Mediator of Superoxide-Dependent Injury. In: Oxidative Damage \& Repair. Elsevier; 1991. p. 251-255. 
59. Yao D, Gu Z, Nakamura T, et al. Nitrosative stress linked to sporadic Parkinson's disease: S-nitrosylation of parkin regulates its E3 ubiquitin ligase activity. Proc Natl Acad Sci U S A. 2004;101(29):10810-10814.

60. Manning BD, Cantley LC.AKT/PKB signaling: Navigating downstream Cell. 2009;129(7):1261-1274.

61. Lim JH, Kim KM, Kim SW, et al. Bromocriptine activates NQO1 via Nrf2-PI3K/Akt signaling: Novel cytoprotective mechanism against oxidative damage. Pharmacol Res. 2008;57(5):325-331.

62. Ries V, Henchcliffe C, Kareva T, et al. Oncoprotein Akt/PKB induces trophic effects in murine models of Parkinson's disease. Proc Natl Acad Sci U S A. 2006;103(49):18757-18762.

63. Malagelada C, Jin ZH, Greene LA. RTP801 is induced in Parkinson's disease and mediates neuron death by inhibiting Akt phosphorylation/ activation. J Neurosci. 2008;28(53):14363-14371.

64. Schapira AH, Cooper JM, Dexter D, et al. Mitochondrial complex I deficiency in Parkinson's disease. J Neurochem. 1990;54(3):823-827.

65. Bohush A, Niewiadomska G, Filipek A. Role of Mitogen Activated Protein Kinase Signaling in Parkinson's Disease. Int $\mathrm{J}$ Mol Sci. 2018;19(10):2973.

66. Cheung ECC, Slack RS. Emerging role for ERK as a key regulator of neuronal apoptosis. Sci STKE. 2004;2004(251):PE45.

67. Taymans J-M, Baekelandt V, Harvey K. Regulation and targeting of enzymes mediating Parkinson's disease pathogenesis: Focus on Parkinson's disease Kinases, GTPases and ATPases. Front Mol Neurosci. 2014;7:71.

68. Ibáñez P, Bonnet A-M, Débarges B, et al. Causal relation between $\alpha-$ synuclein locus duplication as a cause of familial Parkinson's disease. Lancet. 2004;364(9440):1169-1171.

69. Klein C, Westenberger A. Genetics of Parkinson's Disease. Cold Spring Harb Perspect in Med. 2012;2(1)a008888.

70. Mata IF, Wedemeyer WJ, Farrer MJ, et al. LRRK2 in Parkinson's disease: Protein domains and functional insights. Trends Neurosci. 2006;29(5):286-293.

71. Gaig C, Martí MJ, Ezquerra M, et al. G2019S LRRK2 mutation causing Parkinson's disease without Lewy bodies. J Neurol Neurosurg Psychiatry. 2007;78(6):626-628.

72. Di Rita A, Maiorino T, Bruqi K, et al. MiR-218 Inhibits Mitochondrial Clearance by Targeting PRKN E3 Ubiquitin Ligase. Int $J$ Mol Sci. 2020;21(1):355.

73. Poole AC, Thomas RE, Andrews LA, et al. The PINK1/Parkin pathway regulates mitochondrial morphology. Proc Natl Acad Sci U SA. 2008;105(5):1638-1643.

74. Guardia-Laguarta C, Liu Y, Lauritzen KH, et al. PINK1 Content in Mitochondria is Regulated by ER-Associated Degradation. J Neurosci. 2019;39(36):7074-7085.

75. Bandopadhyay R, Kingsbury AE, Cookson MR, et al. The expression of DJ $\square 1$ (PARK7) in normal human CNS and idiopathic Parkinson's disease. Brain. 2004;127(2):420-430.

76. Houghton PJ, Howes MJ. Natural Products and Derivatives Affecting Neurotransmission Relevant to Alzheimer's and Parkinson's Disease. Neurosignals. 2005;14(1-2):6-22.

77. Sengupta T, Vinayagam J, Singh R, et al. Plant-Derived Natural Products for Parkinson's Disease Therapy. In: Essa MM, Akbar M, Guillemin G, editors. The Benefits of Natural Products for Neurodegenerative Diseases. Cham: Springer International Publishing; 2016. p. 415-496.

78. Aruoma OI, Halliwell B, Hoey BM, et al. The antioxidant action of N-acetylcysteine: Its reaction with hydrogen peroxide, hydroxyl radical, superoxide, and hypochlorous acid. Free Radic Biol Med. 1989;6(6):593-597.
79. Clark J, Clore EL, Zheng K, et al. Oral N-Acetyl-Cysteine Attenuates Loss of Dopaminergic Terminals in $\alpha$-Synuclein Overexpressing Mice. PLoS One. 2010;5(8):e12333.

80. Holmay MJ, Terpstra M, Coles LD, et al. N-Acetylcysteine boosts brain and blood glutathione in Gaucher and Parkinson diseases. Clin Neuropharmacol. 2013;36(4):103-106.

81. Martínez-Banaclocha MA. N-acetyl-cysteine in the treatment of Parkinson's disease. What are we waiting for? Med Hypotheses. 2012;79(1):8-12.

82. Shivalingappa PC, Jin H, Anantharam V, et al. N-Acetyl Cysteine Protects against Methamphetamine-Induced Dopaminergic Neurodegeneration via Modulation of Redox Status and Autophagy in Dopaminergic Cells. Parkinsons Dis. 2012;2012:424285.

83. Unnithan AS, Jiang Y, Rumble JL, et al. N-Acetyl cysteine prevents synergistic, severe toxicity from two hits of oxidative stress. Neurosci Lett. 2014;560:71-76.

84. Bieschke J, Russ J, Friedrich RP, et al. EGCG remodels mature $\alpha-$ synuclein and amyloid- $\beta$ fibrils and reduces cellular toxicity. Proc Natl Acad Sci USA. 2010;107(17):7710-7715.

85. Choi JY, Park CS, Kim DJ, et al. Prevention of Nitric Oxide-Mediated 1-Methyl-4-Phenyl-1,2,3,6-Tetrahydropyridine-Induced Parkinson's Disease in Mice by Tea Phenolic Epigallocatechin 3-Gallate. NeuroToxicology. 2002;23(3):367-374.

86. Chung WG, Miranda CL, Maier CS. Epigallocatechin gallate (EGCG) potentiates the cytotoxicity of rotenone in neuroblastoma SH-SY5Y cells. Brain Res. 2007;1176:133-142.

87. Ehrnhoefer DE, Bieschke J, Boeddrich A, et al. EGCG redirects amyloidogenic polypeptides into unstructured, off-pathway oligomers. Nat Struct Mol Biol. 2008;15(6):558-566.

88. Kim JS, Kim JM, O J-J, et al. Inhibition of inducible nitric oxide synthase expression and cell death by (-)-epigallocatechin-3-gallate, a green tea catechin, in the 1-methyl-4-phenyl-1,2,3,6-tetrahydropyridine mouse model of Parkinson's disease. J Clin Neurosci. 2010;17(9):1165-1168.

89. Xu Y, Zhang Y, Quan Z, et al. Epigallocatechin Gallate (EGCG) Inhibits Alpha-Synuclein Aggregation: A Potential Agent for Parkinson's Disease. Neurochem Res. 2016;41(10):2788-2796.

90. Cleren C, Yang L, Lorenzo B, et al. Therapeutic effects of coenzyme Q10 (CoQ10) and reduced CoQ10 in the MPTP model of Parkinsonism: Coenzyme Q10 and MPTP. J Neurochem. 2008;104(6):1613-1621.

91. Horvath TL, Diano S, Leranth C, et al. Coenzyme Q Induces Nigral Mitochondrial Uncoupling and Prevents Dopamine Cell Loss in a Primate Model of Parkinson's Disease. Endocrinology. 2003;144(7):2757-2760.

92. Müller T, Büttner T, Gholipour AF, et al. Coenzyme Q10 supplementation provides mild symptomatic benefit in patients with Parkinson's disease. Neurosci Lett. 2003;341(3):201-204.

93. Shults CW, Oakes D, Kieburtz K, et al. Effects of Coenzyme Q10 in Early Parkinson Disease: Evidence of Slowing of the Functional Decline. Arch Neurol. 2002;59(10):1541.

94. Shults CW. Therapeutic role of coenzyme Q10 in Parkinson's disease. Pharmacol Ther. 2005;107(1):120-130.

95. Yoritaka A, Kawajiri S, Yamamoto Y, et al. Randomized, double-blind, placebo-controlled pilot trial of reduced coenzyme Q10 for Parkinson's disease. Parkinsonism Relat Disord. 2015;21(8):911-916.

96. Ahmad M, Saleem S, Ahmad AS, et al. Neuroprotective effects of Withania somnifera on 6-hydroxydopamine induced Parkinsonism in rats. Hum Exp Toxicol. 2005;24(3):137-147.

97. Bhattacharya SK, Satyan KS, Ghosal S. Antioxidant activity of glycowithanolides from Withania somnifera. Indian J Exp Biol. 1997;35(3):236-239. 
98. Manjunath MJ, Muralidhara. Standardized extract of Withania somnifera (Ashwagandha) markedly offsets rotenone-induced locomotor deficits, oxidative impairments and neurotoxicity in Drosophila melanogaster. $J$ Food Sci Technol. 2015;52(4):1971-1981.

99. Prakash J, Yadav SK, Chouhan S, et al. Neuroprotective Role of Withania somnifera Root Extract in Maneb-Paraquat Induced Mouse Model of Parkinsonism. Neurochem Res. 2013;38(5):972-980.

100. Prakash J, Chouhan S, Yadav SK, et al. Withania somnifera Alleviates Parkinsonian Phenotypes by Inhibiting Apoptotic Pathways in Dopaminergic Neurons. Neurochem Res. 2014;39(12):2527-2536.

101. Raja Sankar S, Manivasagam T, Surendran S. Ashwagandha leaf extract: A potential agent in treating oxidative damage and physiological abnormalities seen in a mouse model of Parkinson's disease. Neurosci Lett. 2009;454(1):11-15.

102. RajaSankar S, Manivasagam T, Sankar V, et al. Withania somnifera root extract improves catecholamines and physiological abnormalities seen in a Parkinson's disease model mouse. J Ethnopharmacol. 2009;125(3):369-373.

103. Choi JH, Jang M, Nah S-Y, et al. Multitarget effects of Korean Red Ginseng in animal model of Parkinson's disease: antiapoptosis, antioxidant, antiinflammation, and maintenance of blood-brain barrier integrity. J Ginseng Res. 2018;42(3):379-388.

104. Kitts DD, Wijewickreme AN, Hu C. Antioxidant properties of a North American ginseng extract. Mol Cell Biochem. 2000;203(1-2):1-10.

105. Van Kampen J, Robertson H, Hagg T, et al. Neuroprotective actions of the ginseng extract G115 in two rodent models of Parkinson's disease. Exp Neurol. 2003;184(1):521-529.

106. Wang CN, Shiao YJ, Kuo YH, et al. Inducible Nitric Oxide Synthase Inhibitors from Saposhnikovia divaricata and Panax quinquefolium. Planta Med. 2000;66(7):644-647.

107. Zhou T, Zu G, Zhang X, et al. Neuroprotective effects of ginsenoside Rg1 through the Wnt/ $\beta$-catenin signaling pathway in both in vivo and in vitro models of Parkinson's disease. Neuropharmacology. 2016;101:480-489.

108. Rojas P, Ruiz-Sánchez E, Rojas C, et al. Ginkgo biloba extract (EGb 761) modulates the expression of dopamine-related genes in 1methyl-4-phenyl-1,2,3,6-tetrahydropyridine-induced Parkinsonism in mice. Neuroscience. 2012;223:246-257.
109. Yoshitake T, Yoshitake S, Kehr J. The Ginkgo biloba extract EGb 761® and its main constituent flavonoids and ginkgolides increase extracellular dopamine levels in the rat prefrontal cortex: Ginkgo increases cortical dopamine. Br J Pharmacol. 2010;159(3):659-668.

110. Yu D, Zhang P, Li J, et al. Neuroprotective effects of Ginkgo biloba dropping pills in Parkinson's disease. J Pharm Anal. 2020;20(1):53-57.

111. Zuo W, Yan F, Zhang B, et al. Advances in the Studies of Ginkgo Biloba Leaves Extract on Aging-Related Diseases. Aging Dis. 2017;8(6):812826

112. Cheng Y, He G, Mu X, et al. Neuroprotective effect of baicalein against MPTPneurotoxicity: Behavioral, biochemical and immunohistochemical profile. Neurosci Lett. 2008;441(1):16-20.

113. Lee HJ, Noh YH, Lee DY, et al. Baicalein attenuates 6hydroxydopamine-induced neurotoxicity in SH-SY5Y cells. Eur J Cell Biol. 2005;84(11):897-905.

114. Li Y, Zhao J, Hölscher C. Therapeutic Potential of Baicalein in Alzheimer's Disease and Parkinson's Disease. CNS Drugs. 2017;31(8):639-652.

115. Shang YZ, Qin B-, Cheng JJ, Miao H. Prevention of oxidative injury by flavonoids from stems and leaves of Scutellaria Baicalensis georgi in PC12 cells. Phytother Res. 2006;20(1):53-57.

116. Khatri DK, Juvekar AR. Propensity of Hyoscyamus niger seeds methanolic extract to allay stereotaxically rotenone-induced Parkinson's disease symptoms in rats. Orient Pharm Exp Med. 2015;15(4):327-339.

117. Nagashayana N, Sankarankutty P, Nampoothiri MRV, et al. Association of 1-DOPA with recovery following Ayurveda medication in Parkinson's disease. J Neurol Sci. 2000;176(2):124-127.

118. Sengupta T, Vinayagam J, Nagashayana N, et al. Antiparkinsonian Effects of Aqueous Methanolic Extract of Hyoscyamus niger Seeds Result From its Monoamine Oxidase Inhibitory and Hydroxyl Radical Scavenging Potency. Neurochem Res. 2011;36(1):177-186. 